\section{Pothole Community Management for Livestock and Wildlife in the Intermountain Region ${ }^{1}$}

\section{FRANK GUNNELL AND ALLEN G. SMITH2}

Wildlife Biologist, Cache National Forest, $U$. S. Forest Service, Logan; and

Formerly Wildlife Biologist, Fish and Wildlife Service, Brigham City, Utah.

\section{Highlight}

Potholes are depressions of glacial origin occurring on the prairies of northern United States and in some of the Intermountain glaciated valleys. Intermountain potholes provide excellent wetland habitat for numerous species of migratory waterfowl, waders, game and non-game marsh associated birds. Most of the Intermountain pothole areas are located on public lands and are important sources of water for grazing livestock. Grazing is a land use compatible with wildlife needs if ranges are not overgrazed or livestock concentrated around available watering sites. This study was made with the intent of presenting a management plan whereby wildlife and livestock could jointly occupy these pothole arcas of the forcst lands of the northern Intermountain Forest Region to the benefit of both. Ecological stability rather than environmental competition was the goal with application over wide areas of the inter. mountain west. The study identifies opportunities in designing range developments to complement waterfowl and other species of wildlife on glacial terrain.

As part of the Forest Service White Cloud-BoulderPioneer Land Use Planning study, an analysis was made of the interrelationships between range use and wildlife. In the Copper Basin pothole area on the Challis National Forest, a case was identified in which a range use and wildlife were found to be complementary. The primary purpose of the analysis were:

1. To make an ecological evaluation of the waterfowl habitat in the glacial, lateral moraines of the Copper Basin, in the light of their present condition and future potential;

${ }^{1}$ Contribution of the U. S. Forest Service Region 4, White Clouds-Boulder-Pioneer Comprehensive Land Use Study.

${ }^{2}$ Retired. Formerly with U. S. Fish and Wildlife Service, Brigham City, Utah.
2. To make an appraisal of and suggestions regarding the economics of improving existent potholes or constructing new ones that would further the reproductive potential of wildlife without interfering with the present utilization of the range by livestock.

\section{Description of the Area}

Copper Basin is located in the upper drainage of the East Fork of the Big Lost River in the Challis National Forest, approximately 40 miles northwest of $\Lambda$ rco, Idaho. It is a high mountain valley $(7,800+\mathrm{ft}$ altitude), sheltered by the Pioneer Mountains on the west and the White Knob Mountains on the east. Occupying a very prominent position in the basin is a lateral moraine that was thrust up by a glacier that moved north out of valleys to the south. This moraine is about five milcs long, over 500 fect above the valley floor, and from two to three miles in width. The path of the glacier pushed up this lateral moraine on its right flank in the center of the valley (Copper Basin Moraine) its left flank scoured the base of the Pioneer Mountains leaving only a narrow, bench-like moraine (West Moraine). This bench has been dissected by the drainages of many springs, seeps, and successive spring run-offs.

The Copper Basin Moraine is dotted with depressions of varying sizes, shapes, and depths. Some contain water throughout the year; some only until mid-summer; others are dry except following spring run-off. Disregarding the differences in altitude and topography, these morainal potholes are closely related to the semi-arid, lateral moraines of southern Alberta and Saskatchewan. In this area summer temperatures, spring run-off, and summer precipitation control the quality and quantity of surface water and the presence or abscnce of watcrfowl and associated birds. The higher altitude of this area of study is, to a great extent, balanced by the low altitude but higher latitude of the Canadian pothole habitats.

Copper Basin has a growing season extending from June 1-15, through August 1-September 1. Potholes are ice-free between May 15-June 1 and freeze-up which normally occurs about October 1. 


\section{Characteristics of the Potholes}

The Copper Basin Moraine is dotted with hundreds of pothole basins. Eighteen of them are spring fed and contain water throughout the year. Others are semi-permanent in nature, holding water in the early weeks of the season but drying before fall, except in years of heavy summer precipitation. The most common type is the temporary pothole which normally fills after spring run-off but is dry by mid or late June. The shallow temporary and semi-permanent potholes are frequently located over seeps or sumps, but as the water table lowers during the summer, a break occurs between the surface water and the water table and desiccation results. Because the drying of temporary potholes takes place so early in the summer, their presence in late summer is marked only by small meadows in slight depressions, surrounded by sagebrush (Artemisia spp.), forbs, and grasses characteristic of the nearby uplands.

Most permanent potholes, including beaver ponds, contain some aquatic vegetation. Most common are the clasping-leaved pondweed (Potamogeton richardsonii) and the white water buttercup (Ranunculus aquatilis). Mare's tail (Hippuris vulgaris) and arrowheads (Sagittaris spp.) are present in lesser quantities. The common duck weed (Lemna minor) is common in the beaver ponds. Because of heavy trampling of pothole shorelines by cattle, aquatic plants are able to survive only at depths greater than two feet. In beaver ponds where grazing has been light because of aspen slash surrounding them, carpets of the needle rush (Eleocharis acicularis) grown in the shallow water and mucky or sandy shores.

The most common emergent plant of the beaver ponds and moranial potholes is the common large spikerush (Eleocharis palustris). Several species of sedges are also present on the shores of the beaver ponds, the most common being the clump sedge (Carex atherodes). These ponds are also rimmed with small shrubs and trees such as shrubby cinquefoil (Potentilla fruticosa), aspen (Populus balsamifera), willows (Salix spp.), and alpine fir (Abies lasiocarpa).

\section{Inventory of Wildlife and Livestock}

Several species of waterfowl and associated birds breed in or near the Copper Basin moraines. A list of these birds with prevalence rating follows in which $\mathrm{C}=$ common, $\mathrm{O}=$ occasional, and $\mathbf{R}=$ rare: mallard $(\mathrm{C})$, pintail $(\mathrm{C})$, green-winged teal $(\mathrm{O})$, blue-winged teal $(R)$, cinnamon teal $(R)$, baldpate $(O)$, shoveler $(O)$, redhead $(\mathrm{O})$, common merganser $(\mathrm{O})$, horned grebe $(\mathrm{O})$, great blue heron $(\mathrm{O})$, coot $(\mathrm{C})$, killdeer $(\mathrm{C})$, upland plover $(\mathrm{O})$, and spotted sandpiper $(\mathrm{O})$.

Between 500 and 600 antelope are summer residents in the basin, a deer migration route crosses the area, and an elk calving ground is located there. Several hundred sage grouse summer in the basin but are more

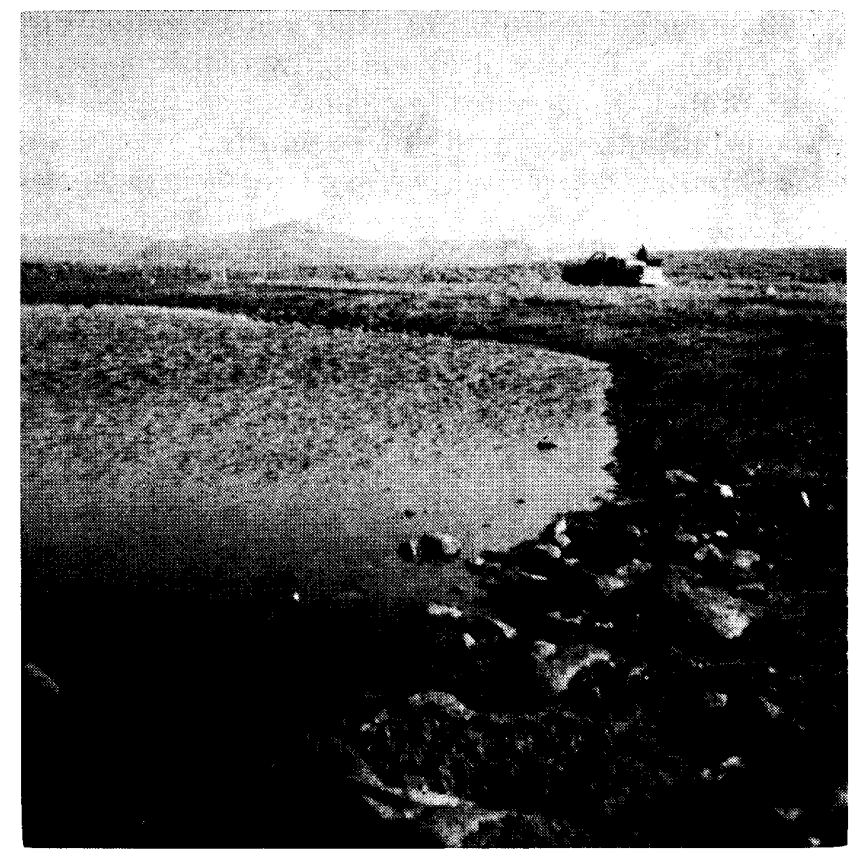

FIG. 1. Permanent pothole devoid of shoreline vegetation because of livestock concentrations.

or less concentrated near the permanent potholes as their source of water.

The entire basin, including the moraines, contains 100,000 acres, of which 60,000 are suitable livestock range. Approximately 3,400 cattle graze the basin between June 10-July 1 and October 15-November 1 . Considering only the grazed acres, there is a livestock/ acreage relationship of 17 acres/head of stock.

Big game, waterfowl, and associated birds of the potholes and uplands have little or no effect upon the wetland habitats of the basin. Livestock, however, are having a pronounced effect under present conditions.

\section{Competition Between Wildlife and Livestock}

The edges of all Copper Basin potholes are so trampled by concentrations of livestock that there are no emergents or other vegetation in these portions of the potholes wadable by cattle (Fig. 1). The shallow water is fouled with the droppings of cattle and muddied by their wading. One permanent pothole has been so polluted by urine and fecal material that the brown water gave off a strong odor of ammonia; and, though it contained a few surface insects, there were no plants of any kind.

In an effort to rectify this problem, the U. S. Forest Service initiated a program of digging a series of water holes (Fig. 2) to aid in the dispersal of cattle into areas not otherwise utilized by them because of the absence of available water. Approximately three quarters of the planned 460 water holes have now been dug. Basically, this program, should lead to solution of the problem of wildlife-livestock competition 


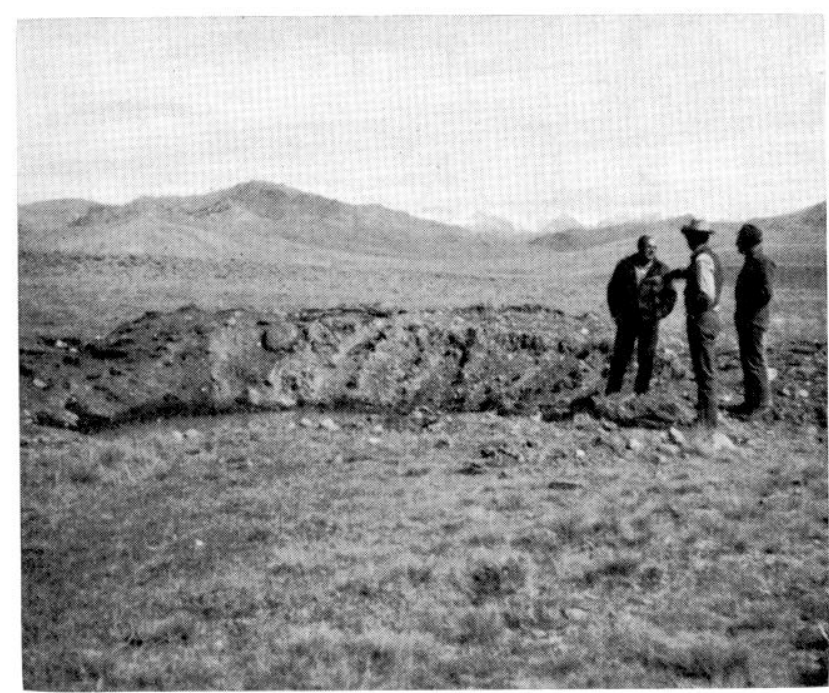

FIG. 2. Dug-outs for watering cattle.

in this pothole area. However, modifications of this plan may not only provide greater access to water by livestock but improve the total environment for all species of wildlife, as a coincident effect.

\section{Discussion and Management Recommendations}

The permanent potholes of the Copper Basin are all capable of attracting several species of waterfowlmost of them do. However, each would be much more attractive to water associated birds through the simple expedient of reducing the pressures of watering livestock at these potholes. If the bare ground that frequently encircles these water areas became revegetated and if emergents and aquatics were able to grow, waterfowl numbers would be increased appreciably. Nesting cover, escape cover, and food supplies-plant and animal-would be so improved as to encourage more breeding waterfowl than are now present and would provide an environment that would attract several species, such as redheads, where now they are only transients.

Each of the water birds known to use the wetland habitat of these ranges would be benefited by the revegetation of pothole shorelines and the encouragement of emergent and aquatic plant growth. The spread of aquatics into shallow water would increase the available plant and insect life used as food by waterfowl. The return of emergent plants to the edges of the potholes would provide nesting cover for redheads, coots, and to a lesser extent for mallards and pintails. A lush growth of upland plants, especially the sedges and rushes, on the wet shorelines would be used as nesting cover by all ducks and escape cover for all water oriented birds. There are plenty of bare areas in the uplands immediately surrounding potholes where killdeer will continue to nest. They require escape cover, however, and emergent vegetation would more than fulfill their needs. Upland plover will find increased nesting locations around the potholes and emergent plants would be of benefit to this species and to their young. It is believed that native plants, if allowed to mature, are sufficient to care for the needs of waterfowl.

Escape cover is particularly important for nesting water birds on range lands because of the variety of birds and mammals that may prey upon adult birds, their eggs, or their young. This should not be construed to infer a need for predator control for these birds. Natural conditions that lead to a normal predator-prey relationship are to be sought at all times. Though food and water are necessary requirements to attract ducks and associated birds to range land potholes, nesting and escape cover are equally important if the birds are to produce and rear young successfully. Present conditions of the aquatic habitat in many areas reduces this possibility to a minimum.

Studies of morainal potholes in the prime waterfowl habitat of western United States and Canada have shown that semi-permanent potholes attract the greatest densities and varieties of breeding ducks. Permanent potholes, though they most always attract breeding ducks are particularly during drought years when they act as "safety" areas, do not usually contain the abundance and variety of plant and animal life that is found in semi-permanent potholes. Therefore, if some of the semi-permanent potholes can be maintained for a period longer than at present, the waterfowl population will be increased.

One of the best possibilities, and one that should bring the greatest return for the least labor and money, would be to concentrate on the creation and maintenance of several "communities of potholes" (Fig. 3). A community of potholes or a pothole complex contains several bodies of water of different degrees of permanence, size, shape, depth, and vegetative cover. Their presence insures their use by the largest number of waterfowl species as well as by the largest number of individuals of those species.

"The sum of all the interrelationships between ducks, habitat, weather, land use, and many other less obvious factors, basically the ecology of the species, ultimately determines the productivity of the birds. As a pair of ducks is the fundamental productive unit, the focus of management should be directed toward its needs, with the greatest emphasis on the dangerous six weeks between nest construction and the hatch of the clutch. If habitat requirements for that period have been met, brood survival will take care of itself." 3

With the above statement in mind, there are many possibilities in the western rangelands for stabilizing communities of potholes that already contain a permanent pothole and several satellites that are both semipermanent and temporary in nature. If one such com-

${ }^{3}$ Smith, Allen G. In Press. Ecological Factors Affecting Waterfowl Production in the Alberta Parklands. 


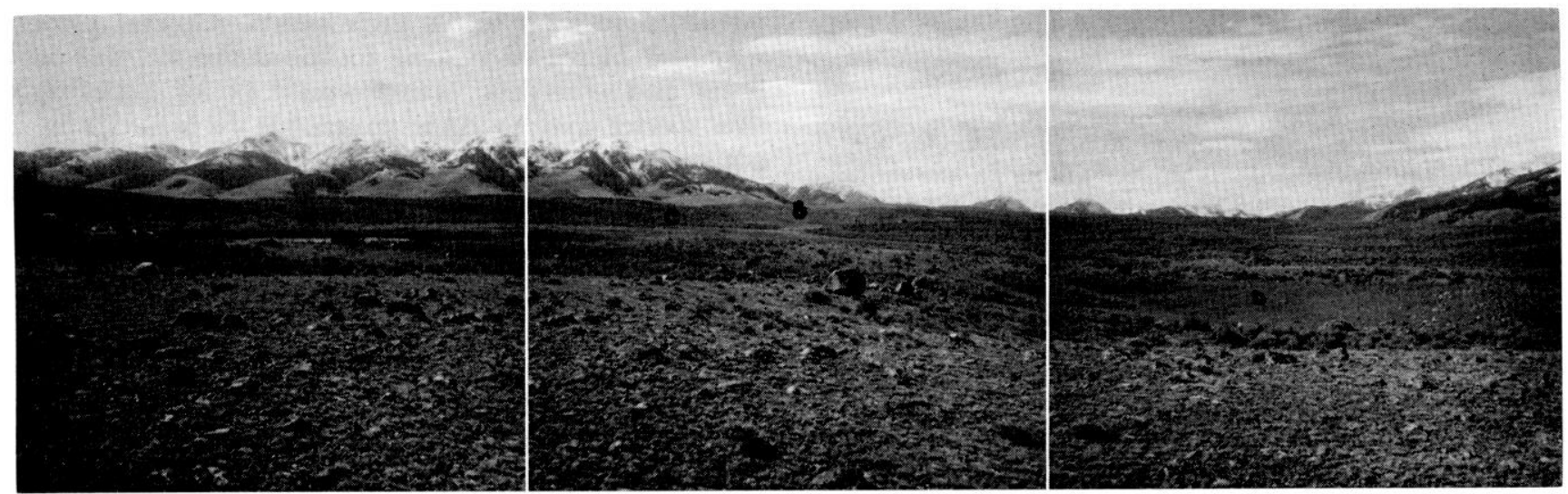

FIc. 3. Community of potholes illustrating three degrees of water permanence.

munity, as illustrated in Figure 3, were to be the subject of development, it would be necessary to fence off all but a livestock watering area in the permanent pothole $\mathrm{A}$, open the seep or spring in pothole $\mathrm{B}$, encourage the drainage of water from $\mathrm{B}$ to $\mathrm{C}$ and/or $\mathrm{D}$ with a shallow, $\mathrm{V}$-shaped trench. The complete fencing of this community of potholes, except for $1 / 4$ of a pothole $\mathrm{A}$, as an access lane for cattle, would establish one of the finest of wetland habitats for water birds grassland water bird habitats. A development of this type would provide the maximum of results with the minimum of costs and disturbance.

This same type of management could be executed on similar depressions as those illustrated in Figure 3. Many others, scattered throughout the western range lands, can be managed in a like manner, giving priority to low costs and greatest benefits to both wildlife and livestock. The beneficial effects would enhance the upland and wetland habitats of our western ranges.

\section{Conclusions}

Cattle grazing and waterfowl use complement each other just so long as overgrazing and competion for water are not a part of the scene. In some areas cattle are in direct competition with waterfowl and other water associated birds in and around the potholes. It is caused by heavy grazing of upland vegetation immediately surrounding the potholes and the loss of shallow water emergents because of localized trampling by heavy concentrations of stock. It has resulted in the fouling of the water, the destruction of nesting and escape cover, and the confinement of aquatic plants to deep water.

Where there is a desire to benefit waterfowl and associated wildlife as well as cattle, a program of developing water holes scattered throughout the glacial moraines of our western range lands, will be of great value. It will aid in the dispersal of cattle and antelope, open up new areas to sage grouse, and result in a better utilization of the ranges in areas formerly too far from water to be grazed by stock. Most important, as a benefit to waterfowl, would be the development of a small number of pothole communities or complexes scattered throughout the same range lands. If these developed wetland communities are successfully excluded from concentrations of livestock, except at designated locations, it should result in appreciable increases in the present waterfowl populations of morainal range lands. We see no reason why these increases would not continue in proportion to the number of pothole communities so treated. Nearly all wildlife that inhabit western range lands would be benefited if permanent potholes were protected from heavy grazing by livestock and communities of potholes were developed and assured of some permanence and protection. Water tables in morainal pothole areas are normally high, a condition which lends itself to maximum benefits for livestock and wildlife through a minimum of excavation while requiring minimal expenditures.

To adequately fulfill its mission the Journal of Range Management should strive continually to broaden its scope and improve the quality of its contents. A growing journal is one which provides a maximum of reader satisfaction through its choice of pertinent, well-written articles of lasting value expressed in terms understandable by the technical and practical man alike. It is hoped that the Journal may be considered a medium for publication by all investigators in range management. Robert A. Darrow. J. Range Manage. 7:2. 